\title{
Evaluating Safety and Efficacy of Follow-up for Patients With Abdominal Pain Using Video Consultation (SAVED Study): Randomized Controlled Trial
}

Dinesh Visva Gunasekeran ${ }^{1,2^{*}}$, MBBS; Zhenghong Liu ${ }^{1 *}$, MBBS; Win Jim Tan ${ }^{1}$, MBBS; Joshua Koh ${ }^{1}$, MBBS; Chiu Peng Cheong ${ }^{1}$; Lay Hong Tan $^{1}$; Chee Siang Lau ${ }^{1}$; Gaik Kheng Phuah ${ }^{1}$; Newsie Donnah A Manuel ${ }^{1}$; Che Chong Chia ${ }^{1}$; Gek Siang Seng ${ }^{1}$; Nancy Tong ${ }^{1}$; May Hang Huin ${ }^{1}$; Suzette Villaluna Dulce ${ }^{1}$; Susan Yap ${ }^{1}$; Kishanti Ponampalam ${ }^{1}$; Hao Ying ${ }^{3}$, PhD; Marcus Eng Hock Ong ${ }^{1,3,4}$, MBBS, FRCSE; R Ponampalam ${ }^{1}$, MBBS, FRCSE

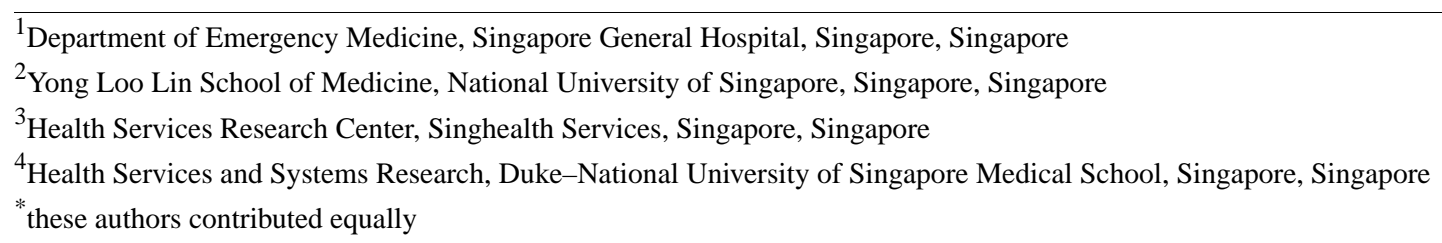

Corresponding Author:

R Ponampalam, MBBS, FRCSE

Department of Emergency Medicine

Singapore General Hospital

Singapore

Singapore

Phone: 6563213497

Email: ponampalam@singhealth.com.sg

\section{Abstract}

Background: The benefits of telemedicine include cost savings and decentralized care. Video consultation is one form that enables early detection of deteriorating patients and promotion of self-efficacy in patients who are well but anxious. Abdominal pain is a common symptom presented by patients in emergency departments. These patients could benefit from video consultation, as it enables remote follow-up of patients who do not require admission and facilitates early discharge of patients from overcrowded hospitals.

Objective: The study aimed to evaluate the safety and efficacy of the use of digital telereview in patients presenting with undifferentiated acute abdominal pain.

Methods: The SAVED study was a prospective randomized controlled trial in which follow-up using existing telephone-based telereview (control) was compared with digital telereview (intervention). Patients with undifferentiated acute abdominal pain discharged from the emergency department observation ward were studied based on intention-to-treat. The control arm received routine, provider-scheduled telereview with missed reviews actively coordinated and rescheduled by emergency department staff. The intervention arm received access to a platform for digital telereview (asynchronous and synchronous format) that enabled patient-led appointment rescheduling. Patients were followed-up for 2 weeks for outcomes of service utilization, efficacy (compliance with their disposition plan), and safety (re-presentation for the same condition).

Results: A total of 70 patients participated, with patients randomly assigned to each arm (1:1 ratio). Patients were a mean age of 40.0 (SD 13.8; range 22-71) years, predominantly female (47/70, 67\%), and predominantly of Chinese ethnicity (39/70, 56\%). The telereview service was used by 32 patients in the control arm $(32 / 35,91 \%)$ and 18 patients in the intervention arm $(18 / 35$, $51 \%)$. Most patients in control (33/35, 94\%; 95\% CI 79.5\%-99.0\%) and intervention (34/35, 97\%; 95\% CI 83.4\%-99.9\%) arms were compliant with their final disposition. There was a low rate of re-presentation at 72 hours and 2 weeks for both control (72 hours: $2 / 35,6 \% ; 95 \%$ CI 1.0\%-20.5\%; 2 weeks: $2 / 35,6 \%, 95 \%$ CI 1.0\%-20.5\%) and intervention (72 hours: $2 / 35,6 \%$; $95 \%$ CI $1.0 \%-20.5 \%$; 2 weeks: $3 / 35,9 \%, 95 \%$ CI $2.2 \%-24.2 \%)$ arms. There were no significant differences in safety $(P>.99)$ and efficacy $(P>.99)$ between the two groups.

Conclusions: The application of digital telereview for the follow-up of patients with abdominal pain may be safe and effective. Future studies are needed to evaluate its cost-effectiveness and usefulness for broader clinical application. 
Trial Registration: ISRCTN Registry ISRCTN28468556; http://www.isrctn.com/ISRCTN28468556.

(J Med Internet Res 2020;22(6):e17417) doi: $10.2196 / 17417$

\section{KEYWORDS}

digital health; teleconsultation; video consultation; telereview; abdominal pain; primary care; emergency department

\section{Introduction}

Existing literature on telemedicine suggests that it enables cost savings and improved health care access for patients with diverse illnesses [1,2]. These reports have fueled a rise in the adoption of telemedicine for these applications in various clinical settings [3], allowing new models for decentralized care that may help alleviate shortages in health care resources and help encourage self-management by patients where appropriate [4]. This need has been heightened with the coronavirus disease 2019 (COVID-19) pandemic which has been placing many health systems in dire straits. The application of video consultation to facilitate early discharge and subsequent remote follow-up of relatively well patients is a potential solution for increasingly oversubscribed emergency departments [5], given the detrimental effects of overcrowding on the timeliness and the quality of care [6].

Patient and provider acceptance of video consultation has grown in recent years, and over two-thirds of respondents to a survey of patient and caregiver acceptance conducted in the emergency department of Singapore General Hospital were comfortable using mobile technology to share information [7]. Prior studies in Singapore have reported benefits from telemedicine such as improved health care access in the form of remote consultation mediated by health professionals for acute illnesses such as poisoning [8] or maritime emergencies [9]; however, few international studies have reported controlled outcomes from the use of telemedicine for acute illnesses by patients directly. Furthermore, many studies had considerable limitations in terms of study design [10] and clarity in reporting which telemedicine interventions were used [11].

The use of video consultation for telereview has not been conclusively investigated in patients with acute gastrointestinal ailments $[12,13]$. The objective of this study was to evaluate the safety and efficacy of digital telereview for patients in the emergency department who present with undifferentiated acute abdominal pain. In this study, digital telereview was evaluated as a "pull-from-patient", a patient-led form of service delivery, and was compared with existing telephone-based telereview evaluated as a "push-to-patient", a provider-led form of service delivery. This was the first direct and pragmatic trial of these alternative forms of service delivery for the follow-up of patients with abdominal pain.

\section{Methods}

\section{Study Design}

The SAVED (Safety and Efficacy of Follow-up for Patients With Abdominal Pain Using Video Consultation) study was a prospective randomized controlled trial with a 1:1 allocation ratio. An existing telephone-based telereview service (control) was compared with digital telereview using DoctorBell-a novel, web-based telehealth platform (intervention). This study was approved by the Centralized Institutional Review Board of SingHealth Singapore General Hospital (protocol number 2017/2049) and conducted in accordance with the Declaration of Helsinki (2000).

\section{Study Setting}

The emergency department was selected as the location for this pilot study because 24-hour medical services were available to attend to any patients whose condition deteriorated [13]. Patients from the emergency department observation ward with severe undifferentiated illnesses that did not meet clinical criteria for hospital admission were recruited. This cohort represents a segment of the population of patients in the emergency department for whom the decision (final disposition) is delayed by clinical uncertainty $[14,15]$; therefore, the recruitment of patients discharged from the emergency department observation ward allowed investigators to stress-test the appropriateness of disposition assigned by digital telereview as well as patient adherence to recommendations, since telephone-based telereview is routinely conducted within 48 to 72 hours of discharge for patients with undifferentiated illness as a fail-safe measure that enables early detection of patients with deteriorating clinical condition. This practice improves care continuity while enabling safe discharge to address overcrowding.

\section{Study Recruitment}

Patients with undifferentiated acute abdominal pain who were discharged from a tertiary hospital in Singapore using detailed criteria (Abdominal Pain or Gastroenteritis Pathways in Multimedia Appendix 1) were considered for recruitment at the point of discharge by study team members after the patient had received routine treatment and a disposition plan which included counselling for self-efficacy and monitoring at home as well as education regarding clinical features that warrant a return to the emergency department (re-presentation).

From September 2017 to May 2018, consecutive patients who presented to the emergency department and who satisfied the study criteria were recruited. Inclusion criteria were the ability to read in English and the ability to operate smartphone messaging apps (such as WhatsApp). To exclude patients who may be considered vulnerable, exclusion criteria were defined as less than 21 years of age, pregnant, a prisoner, cognitively impaired, or requiring a legal representative for informed consent in Singapore. As a pilot, formal sample size calculation was not possible due to a lack of relevant data.

\section{Randomization and Masking}

After completion of informed consent, participants were randomly assigned by a study team member who withdrew lots 
from a box containing equal numbers of paper indicating either control or intervention. Lots in the box were replenished after each draw by a study team member (S.Y.) who was not involved in clinical care or the implementation of the randomization. At recruitment, study team members provided participants with links to web-based surveys about symptoms to be reported by patients at initial presentation and at follow-up, following recruitment and telereview, respectively. Blinding was not possible in this study.

\section{Intervention}

Follow-up after discharge by telereview is routinely conducted by triage nurses to facilitate early discharge from the observation ward, with follow-up review to ascertain right-siting through prompt identification of deteriorating patients as well as encouraging self-efficacy in well patients who are anxious but who do not need to re-visit the emergency department. During telereview, patients who are well are advised on self-management while patients with ominous symptomatology or deteriorating illness are advised to return to the emergency department for further evaluation. In this study, patients in the control arm received routine, provider-led telephone-based telereview after discharge. Telereview was conducted by the emergency department staff on-shift at the time of the patient's booked appointment. Any missed telereviews were actively and manually rescheduled by staff with three attempted phone calls within 48 to 72 hours following discharge. No further attempt was made to contact patients who were not reached in the 72-hour period or those who declined telereview.

Patients in the intervention arm had access to DoctorBell, a novel telehealth platform accessible on smartphone or desktop by web browsers. This was designed using a design-thinking process based on the context and workflows of an emergency department. It allowed patient-led booking, rescheduling, or cancellation of one digital telereview appointment based on the patient's own individual availability, restricted to 48- to 72-hour window following discharge from the emergency department. Digital telereview appointments through this platform were patient-led and were not actively rescheduled by emergency department staff if missed or cancelled. Before the digital telereview appointment (synchronous teleconsultation with video, voice, and text messaging), patients received an in-app form that allowed them to report important history or symptoms beforehand (asynchronous). This was sent to the emergency department staff on-duty before video consultation, providing them with the opportunity to clarify any uncertainties with the on-duty attending physician before synchronous consultation. Upon starting work, staff could view digital telereview bookings scheduled during their shift and received automated real-time push notifications of any changes made to appointments.

\section{Study Outcomes and Statistical Analysis}

Patients in both groups were followed up for 2 weeks to examine the study outcomes of service utilization (telereview appointments used), efficacy (patient compliance with their final disposition plan), and safety (re-presentation to the emergency department for the same medical problem within 72 hours or within 2 weeks). Initially, service utilization and safety were the only outcome measures planned for investigation; however, study team members observed that not all patients complied with instructions given during telereview to return to the emergency department. Therefore, efficacy was later added to the analysis as an outcome measure using existing data. No change to study procedures was required. For patients who did not receive telereview, the final disposition plan was that given at the point of discharge from the emergency department (ie, self-management and monitoring at home). For patients who received telereview, the final disposition plan was that given during telereview (ie, whether to continue self-management or return to the emergency department).

The study population was analyzed based on intention-to-treat. All hypotheses were two-sided with a $P<.05$ considered statistically significant. Descriptive statistical analysis was conducted using SPSS software (version 20.0; IBM Corp). Associations between categorical variables were analyzed using Fisher exact test. Where expected counts within all categories were greater than 5, chi-square test was used instead. Associations between continuous variables were analyzed using the two-tailed two-sample $t$ test.

\section{Results}

From September 2017 to May 2018, patients $(\mathrm{N}=72)$ who were discharged from the emergency department observation ward and who satisfied inclusion criteria were recruited to participate in this study. One patient was under the age of 21 and was excluded. Another patient declined to participate in the study. The remaining patients $(\mathrm{N}=70)$ were enrolled with patients $(n=35)$ randomized to each arm (CONSORT diagram, Figure 1). One patient crossed over from digital telereview to telephone-based telereview since, rather than booking a digital telereview appointment, the patient called the emergency department within 72 hours to report persistent symptoms and complied with instructions to return to the emergency department the next day (on the fourth day postdischarge). This patient was analyzed in the intervention arm in accordance with intention-to-treat.

There were no significant demographic differences between the study groups. Demographics of the study population are described in detail in Table 1. Patients were a mean of 40.0 (SD 13.8; range 22-71) years of age, mostly female (47/70, 67\%) and mostly of Chinese ethnicity (39/70, 56\%). Symptoms reported at initial presentation are detailed in Table 2 and those reported at follow-up are detailed in Table 3 demonstrating the usefulness of a structured web survey in gathering symptomatology during telereview. 
Figure 1. A CONSORT diagram depicting the study. Patients in the control arm receive the push-to-patient form of telephone telereview while patients in the intervention arm receive the pull-from-patient form of digital telereview.

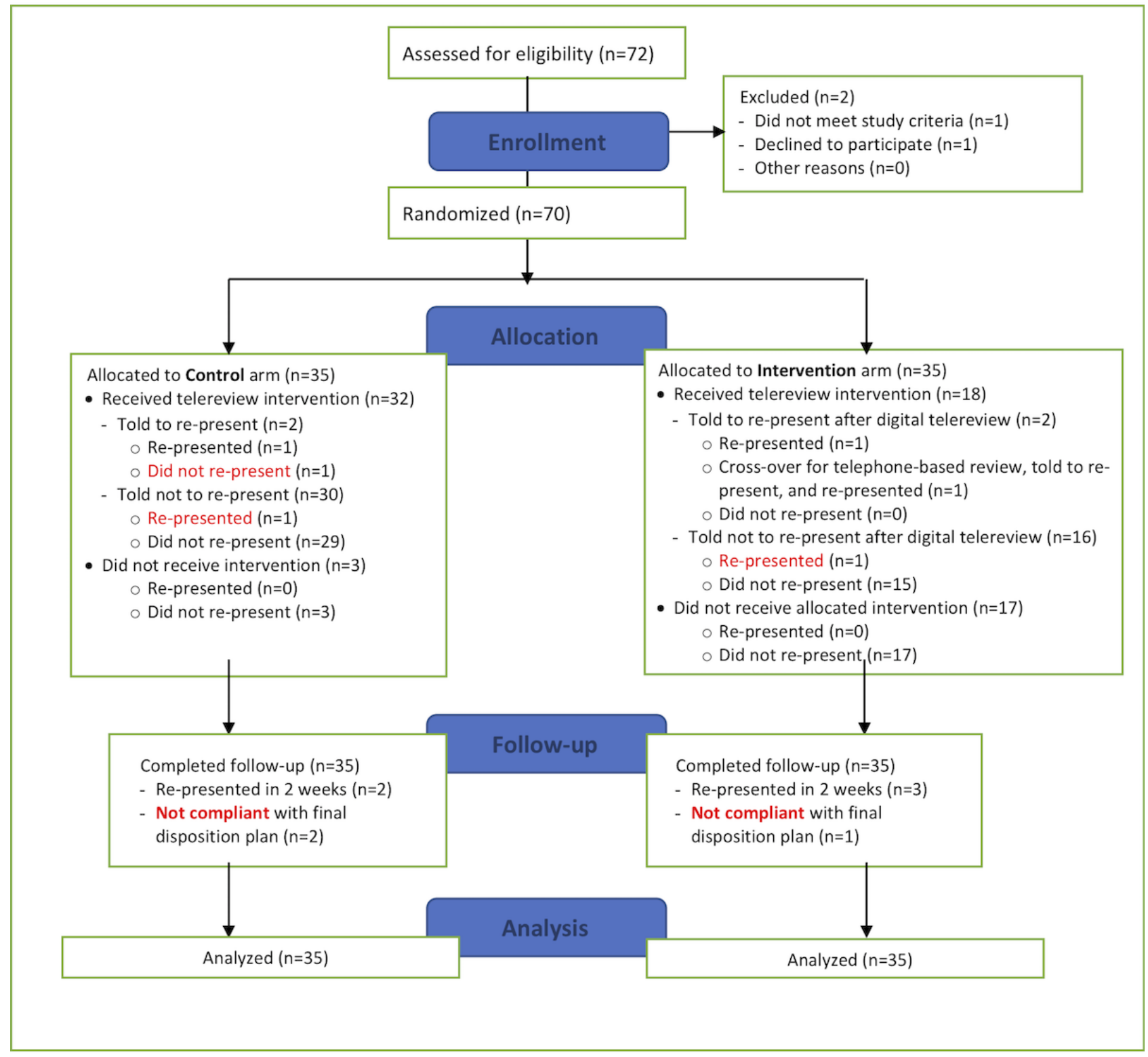


Table 1. Patient Demographics.

\begin{tabular}{|c|c|c|c|c|c|}
\hline Variable & All $(\mathrm{N}=70)$ & DoctorBell $(\mathrm{n}=35)$ & Telephone $(\mathrm{n}=35)$ & Chi-square $(d f)$ & $P$ value \\
\hline Age (years) & & & & $\mathrm{N} / \mathrm{A}^{\mathrm{a}}$ & $.88^{\mathrm{b}}$ \\
\hline mean $(\mathrm{SD})$ & $40.0(13.8)$ & $40.2(13.3)$ & $39.7(14.4)$ & & \\
\hline range & $22-71$ & $26-69$ & $22-71$ & & \\
\hline Gender, n (\%) & & & & $0(1)$ & $>.99$ \\
\hline Male & $23(33)$ & $12(34)$ & $11(31)$ & & \\
\hline Female & $47(67)$ & $23(66)$ & $24(69)$ & & \\
\hline Ethnicity, n (\%) & & & & N/A & 0.38 \\
\hline Chinese & $39(56)$ & $18(51)$ & $21(60)$ & & \\
\hline Malay & $16(23)$ & $7(20)$ & $9(26)$ & & \\
\hline Indian & $6(9)$ & $3(9)$ & $3(9)$ & & \\
\hline Other & $9(13)$ & $7(20)$ & $2(6)$ & & \\
\hline Nationality, n (\%) & & & & N/A & 0.48 \\
\hline Singaporean/Permanent resident & $61(87)$ & $29(83)$ & $32(91)$ & & \\
\hline Other & $9(13)$ & $6(17)$ & $3(9)$ & & \\
\hline Pre-study survey respondent, $n(\%)^{\mathrm{c}}$ & & & & N/A & $>.99$ \\
\hline Patient & $56(92)$ & $28(93)$ & $28(90)$ & & \\
\hline Caregiver & $3(5)$ & $1(3)$ & $2(6)$ & & \\
\hline Both & $2(3)$ & $1(3)$ & $1(3)$ & & \\
\hline Disease manager, $\mathrm{n}(\%)^{\mathrm{c}}$ & & & & N/A & .35 \\
\hline Patient & $56(92)$ & $29(97)$ & $27(87)$ & & \\
\hline Caregiver & $0(0)$ & $0(0)$ & $0(0)$ & & \\
\hline Both & $5(8)$ & $1(3)$ & $4(13)$ & & \\
\hline \multicolumn{4}{|l|}{ Patient highest level of education, $n(\%)^{c}$} & N/A & .38 \\
\hline None & $1(2)$ & $0(0)$ & $1(3)$ & & \\
\hline Primary & $2(3)$ & $2(7)$ & $0(0)$ & & \\
\hline Secondary & $8(13)$ & $2(7)$ & $6(19)$ & & \\
\hline Postsecondary Diploma/Certificate & $19(31)$ & $11(37)$ & $8(26)$ & & \\
\hline Degree & $24(39)$ & $12(40)$ & $12(39)$ & & \\
\hline Masters/PhD & $7(11)$ & $3(10)$ & $4(13)$ & & \\
\hline \multicolumn{4}{|c|}{ Patient needed relative to accompany to hospital, $n(\%)^{c}$} & $0.8(1)$ & .37 \\
\hline Yes & $37(61)$ & $16(53)$ & $21(68)$ & & \\
\hline No & $24(39)$ & $14(47)$ & $10(32)$ & & \\
\hline
\end{tabular}

${ }^{\mathrm{a} N} / \mathrm{A}$ : not applicable as Fisher's exact test was used.

${ }^{\mathrm{b}}$ A two-sided $t$ test was used here.

${ }^{\mathrm{c}}$ This number is less than the group number because respondents did not submit their surveys $(\mathrm{n}=9, \mathrm{n}=5$, and $\mathrm{n}=4$ missing in All, DoctorBell, and Telephone, respectively). 
Table 2. Patient symptoms at presentation to hospital reported in a web-based survey via a link provided following patient recruitment.

\begin{tabular}{|c|c|c|c|c|c|}
\hline Variable & All $(\mathrm{n}=61)^{\mathrm{a}}$ & DoctorBell $(\mathrm{n}=30)^{\mathrm{a}}$ & Telephone $(\mathrm{n}=31)^{\mathrm{a}}$ & Chi-square $(d f)$ & $P$ value \\
\hline Previous abdominal surgery & $14(23)$ & $5(17)$ & $9(29)$ & $0.7(1)$ & .40 \\
\hline Abdominal bloating & $39(64)$ & $20(67)$ & $19(61)$ & $0(1)$ & .87 \\
\hline Loss of appetite & $50(82)$ & $23(77)$ & $27(87)$ & $0.5(1)$ & .47 \\
\hline Fever & $16(26)$ & $9(30)$ & $7(23)$ & $0.1(1)$ & .71 \\
\hline Giddiness & $34(56)$ & $16(53)$ & $18(58)$ & $0(1)$ & .91 \\
\hline Blood in stools & $2(3)$ & $1(3)$ & $1(3)$ & $\mathrm{N} / \mathrm{A}^{\mathrm{b}}$ & $>.99$ \\
\hline Malena & $1(2)$ & $1(3)$ & $0(0)$ & N/A & .49 \\
\hline Diarrhea & $35(57)$ & $16(53)$ & $19(61)$ & $0.1(1)$ & .71 \\
\hline Pale stools & $7(11)$ & $4(13)$ & $3(10)$ & N/A & .71 \\
\hline Nausea/Vomiting & $42(69)$ & $24(80)$ & $18(58)$ & $2.5(1)$ & .12 \\
\hline
\end{tabular}

${ }^{\mathrm{a}}$ This number is less than the group number because respondents did not submit their surveys $(\mathrm{n}=9, \mathrm{n}=5$, and $\mathrm{n}=4$ missing in All, DoctorBell, and Telephone, respectively).

${ }^{\mathrm{b}}$ N/A: not applicable as Fisher's exact test was used.

Table 3. Patient symptoms on follow-up teleconsultation reported in a web-based survey via a link provided following patient recruitment.

\begin{tabular}{|c|c|c|c|c|c|}
\hline Variable & All $(\mathrm{n}=43)^{\mathrm{a}}$ & DoctorBell $(\mathrm{n}=14)^{\mathrm{a}}$ & Telephone $(\mathrm{n}=29)^{\mathrm{a}}$ & Chi-square $(d f)$ & $P$ value \\
\hline Abdominal pain & $12(28)$ & $3(21)$ & $9(31)$ & $\mathrm{N} / \mathrm{A}^{\mathrm{b}}$ & .72 \\
\hline Abdominal bloating & $8(19)$ & $3(21)$ & $5(17)$ & N/A & $>.99$ \\
\hline Diarrhea & $12(28)$ & $3(21)$ & $9(31)$ & N/A & .72 \\
\hline Nausea/vomiting & $3(7)$ & $1(7)$ & $2(7)$ & N/A & $>.99$ \\
\hline Giddiness & $1(2)$ & $0(0)$ & $1(3)$ & N/A & $>.99$ \\
\hline
\end{tabular}

${ }^{\mathrm{a}}$ This number is less than the group number because respondents did not submit their surveys $(\mathrm{n}=9, \mathrm{n}=5$, and $\mathrm{n}=4$ missing in All, DoctorBell, and Telephone, respectively).

b/A: not applicable as Fisher's exact test was used.

There was an overall $71 \%$ (50/70) utilization of the telereview service by 32 patients in the telephone-based telereview control arm $(32 / 35,91 \%)$ and 18 patients in the digital telereview intervention arm $(18 / 35,51 \%)$. Most patients in control (33/35, 94\%; $95 \%$ CI $79.5 \%-99.0 \%)$ and intervention $(34 / 35,97 \%$; 95\% CI 83.4\%-99.9\%) arms were compliant with final disposition. There was a low rate of re-presentation at 72 hours for both arms (control: 2/35, 6\%; 95\% CI 1.0\%-20.5\%; intervention: $2 / 35,6 \% ; 95 \%$ CI $1.0 \%-20.5 \%$ ) and at 2 weeks for both control $(2 / 35,6 \%$; 95\% CI $1.0 \%-20.5 \%)$ and intervention $(3 / 35,9 \% ; 95 \%$ CI $2.2 \%-24.2 \%)$ arms. After the initial 72-hour period, no patients represented within the control arm crossed over whereas the single patient from the intervention arm who crossed over to telephone-based review re-presented at 4 days. Using the chi-square test, there were no significant differences between the control and intervention arms with regards to efficacy as well as safety in terms of re-presentation within 72 hours and within 2 weeks $(P>.99)$.

\section{Discussion}

\section{Principal Findings}

Emergency department overcrowding is a persistent challenge despite increased human resource capacity and process innovations [16] including emergency department observation wards themselves [15]. This has been exacerbated by the COVID-19 pandemic with front-loaded emergency services. New technologies may help resolve overcrowding through automated solutions such as machine learning to optimize existing processes [17] or digital telemedicine to enable new processes that streamline the flow of patients [3]. This study is the first pragmatic randomized controlled trial that evaluated efficacy of digital telereview for the follow-up of patients with undifferentiated acute abdominal pain. This solution uses a hybrid of asynchronous and synchronous teleconsultation-the unique benefits of which have been outlined in a review and case study of their application in eye care [18]. This study is a timely contribution to ongoing debate surrounding the effective implementation of remote consultation in tertiary care. The results of this study suggest that digital telereview may be a safe and effective tool to optimize follow-up processes for right-siting patients in tertiary care.

Digital platforms may enable safe re-design of existing processes from a push-to-patient form of service delivery to a pull-from-patient form. Earlier studies have indicated that patients may not always have adequate insight about the severity of their illness [19]. Hildebrandt et al [19] surveyed primary 
care physicians regarding patient-directed afterhours telephone triage services. Calls from patients who considered their conditions to be non-emergent were reviewed by physicians who found that roughly half of these patients (range 22\%-77\%) required urgent review [19]. In this study, telereview following initial physician contact was selected instead of teletriage in order to ensure that all patients were first counselled by a health professional regarding their condition before intervention.

The use of telereview may not be appropriate in the presence of certain clinical factors. These include patient factors such as lack of insight regarding their health or lack of familiarity with the use of mobile phone technology [7,20]. Some researchers posit that dedicated staff should be rostered to respond to any urgent enquiries and actively follow-up all patients to ensure timely assessment [19]; however, the results from this study indicate that patient-led digital telereview following routine education and discharge advice can be as effective as provider-led active follow-up despite the finding of reduced resource utilization (patient-led digital telereview: 18/35, 51\%; provider-led telephone-based telereview: $32 / 35$, 91\%; Figure $1)$.

This pull-from-patient service delivery reduces manpower utilization to coordinate unnecessary telereview in patients who are well. Findings from a retrospective study of 1522 video-conference teletriage interventions over 52 weeks support this notion that teleconsultation can improve clinical efficiency [21]. Similarly, Brennan et al [22] reported good outcomes and time saved from emergency department teleconsultations. In this study, the digital platform served as a filter to triage patients, saved time for emergency department staff by collecting fundamental patient-reported history asynchronously, and presented the information accessibly to emergency department staff for clarification with the attending physician at any suitable time before synchronous consultation (instead of traditionally having to place the patient on-hold and interrupt the attending for advice). The results from the current study will facilitate the necessary health economic assessments to guide the implementation of digital telereview, which need to be conducted based on relevant outcomes that have been identified in the literature such as reduced adverse events and reduced time requirement [23].

\section{Limitations}

Limitations of this study include a lack of pre-existing data for sample size calculation and possible selection bias since patients were only recruited when study team members were on shift-a common constraint of studies that are conducted in busy emergency departments [13]. Furthermore, these results may not be generalizable given that participants were relatively young and well-educated although, from a practical perspective, such patients are more likely to use digital consultation services [7,23]. Other limitations are consistent with intention-to-treat analysis such as conservative estimates for efficacy as a result of totals diluted by patients who did not receive the intervention (Figure 1). The strengths of intention-to-treat analysis are that it evaluates the actual performance compared objectively with existing practice by considering any deviations in protocol. Further strengths of this study are the use of the gold standard randomized controlled methodology and the comprehensive description of interventions, participants, and outcomes.

Existing reports caution that successful implementation of a telemedicine intervention may not necessarily be reproduced once the clinical application is even slightly modified. This has been observed with investigations of the WelTel telehealth intervention [2]. Lester et al [2] first reported successful implementation of WelTel for messaging that provides weekly automated notifications for patients with Human immunodeficiency virus (and promotes adherence to anti-retroviral therapy with messages based on patient-reported adherence. When van der Kop et al [24] evaluated use of WelTel to promote attendance to follow-up appointments, they found lower compliance in the patients who received the intervention and no significant difference between the groups. Therefore, the results from our study may not be generalizable to other undifferentiated acute presentations such as chest pain. Physicians, administrators, and researchers should be mindful of factors such as clinical context and the form of intervention in the consideration of existing evidence to guide telehealth implementation [20].

The benefits of applying design-thinking in this manner have been described for numerous telehealth applications including tele-ophthalmology enabled by artificial intelligence since contextual considerations such as lack of adequate infrastructure or stable internet access may have an impact on model implementation [25]. In the context of the COVID-19 pandemic, there is a heightened need for providers to evaluate models such as these to rapidly scale health system capacity to address clinical need and to decentralize services to reduce health care-associated transmission [26]. The concurrent use of asynchronous modalities as a filter before synchronous consultation may help ensure better allocation of healthcare manpower similar to the model in this study. Looking beyond the pandemic, when structured appropriately to address the clinical need, digital telereview developed using a design that is mindful of clinical context to guide telehealth implementation (as described above) may lead to considerable cost savings (as suggested by our results). This has already been definitively demonstrated at scale for other related technology applications such as synchronous artificial intelligence-enabled tele-ophthalmology [27] and asynchronous multicenter cloud-computing enabled registry-based research [28].

\section{Conclusions}

Digital telereview may safely facilitate a re-design from a push-to-patient to a pull-from-patient form of follow-up in select patients. This study suggests that there is potential to save cost and manpower-time with digital telereview and has laid the ground work for future investigations to examine the benefits of implementing digital telereview at scale for various clinical applications. 


\section{Acknowledgments}

Patrick Poh Huan Yu, Ming Xiang Tham, and Nicholas Chew Yi Ming are acknowledged as clinical innovators and research collaborators for developing the novel DoctorBell telehealth platform used in this study. The DoctorBell platform was acquired by Mobile Health Pte Ltd on August 1, 2018 and integrated into the MaNaDr telehealth platform.

DVG received travel funding from the Mobile Health Education grant, Commonwealth Fellowship in Innovation award, and the National Youth Fund award for clinical research training and collaborations at Oxford University and Stanford University. The study was partially funded by the Singapore General Hospital in the form of the research hours contributed by study team members employed by the hospital. Funder(s) played no part in the design, conduct, or decision to publish for this study.

This manuscript is dedicated to the memory of our colleague and friend, the late SY, who succumbed to her illness in the months following the completion of this study. She was a dedicated researcher without whom this study among many others would not have been possible. Her passing is a profound loss and her contributions to medicine and clinical sciences will live on.

\section{Conflicts of Interest}

DVG reports investment in DoctorBell, VISRE, AskDr and Shyfts. He reports serving as lecturer and faculty advisor to the medical innovation program of the National University of Singapore, as well as Head of Health Informatics (Collaborative Ocular Tuberculosis Study group).

\section{Multimedia Appendix 1}

Singapore General Hospital (SGH) Emergency Observation Ward Gastroenteritis and Abdominal Pain protocols. [PDF File (Adobe PDF File), 447 KB-Multimedia Appendix 1]

\section{Multimedia Appendix 2}

CONSORT-eHEALTH checklist (V 1.6.1).

[PDF File (Adobe PDF File), 1276 KB-Multimedia Appendix 2]

\section{References}

1. Tuckson RV, Edmunds M, Hodgkins ML. Telehealth. N Engl J Med 2017 Oct 19;377(16):1585-1592. [doi: 10.1056/nejmsr1503323]

2. Lester RT, Ritvo P, Mills EJ, Kariri A, Karanja S, Chung MH, et al. Effects of a mobile phone short message service on antiretroviral treatment adherence in Kenya (WelTel Kenya1): a randomised trial. The Lancet 2010 Nov;376(9755):1838-1845. [doi: 10.1016/s0140-6736(10)61997-6]

3. Ekeland AG, Bowes A, Flottorp S. Effectiveness of telemedicine: a systematic review of reviews. Int J Med Inform 2010 Nov;79(11):736-771. [doi: 10.1016/j.ijmedinf.2010.08.006] [Medline: 20884286]

4. Greenhalgh T, Shaw S, Wherton J, Vijayaraghavan S, Morris J, Bhattacharya S, et al. Real-world implementation of video outpatient consultations at macro, meso, and micro levels: mixed-method study. J Med Internet Res 2018 Apr 17;20(4):e150 [FREE Full text] [doi: 10.2196/jmir.9897] [Medline: 29625956]

5. Morley C, Unwin M, Peterson GM, Stankovich J, Kinsman L. Emergency department crowding: A systematic review of causes, consequences and solutions. PLoS One 2018 Aug 30;13(8):e0203316 [FREE Full text] [doi: 10.1371/journal.pone.0203316] [Medline: 30161242]

6. Lowthian JA, Curtis AJ, Cameron PA, Stoelwinder JU, Cooke MW, McNeil JJ. Systematic review of trends in emergency department attendances: an Australian perspective. Emerg Med J 2011 May 20;28(5):373-377. [doi: 10.1136/emj.2010.099226] [Medline: 20961936]

7. Liu Z, Ng M, Gunasekeran DV, Li H, Ponampalam K, Ponampalam R. Mobile technology: Usage and perspective of patients and caregivers presenting to a tertiary care emergency department. World J Emerg Med 2020;11(1):5-11 [FREE Full text] [doi: 10.5847/wjem.j.1920-8642.2020.01.001] [Medline: $\underline{31892997]}$

8. Ponampalam R, Loh C. Cost Benefits of the Drug and Poison Information Center (DPIC) in preventing unnecessary hospitalization: The Singapore Experience. In. Vol 17: Hong Kong Journal of Emerg Med; 2010:45-53.

9. Lateef F, Anantharaman V. Maritime radio-medical services: the Singapore General Hospital experience. Am J Emerg Med 2002 Jul;20(4):349-351. [doi: 10.1053/ajem.2002.33782] [Medline: 12098185]

10. Mold F, Hendy J, Lai Y, de Lusignan S. Electronic consultation in primary care between providers and patients: systematic review. JMIR Med Inform 2019 Dec 03;7(4):e13042 [FREE Full text] [doi: 10.2196/13042] [Medline: $\underline{31793888]}$

11. Zanaboni P, Lettieri E. Institutionalizing telemedicine applications: the challenge of legitimizing decision-making. J Med Internet Res 2011 Sep 28;13(3):e72 [FREE Full text] [doi: 10.2196/jmir.1669] [Medline: 21955510]

12. The Lancet Gastroenterology \& Hepatology. The potential of telemedicine in digestive diseases. The Lancet Gastroenterology \& Hepatology 2019 Mar;4(3):185. [doi: 10.1016/s2468-1253(18)30359-5] 
13. Heaney D, Caldow J, McClusky C, King G, Webster K, Mair F, et al. The introduction of a new consulting technology into the National Health Service (NHS) for Scotland. Telemed J E Health 2009 Jul;15(6):546-551. [doi: 10.1089/tmj.2009.0017] [Medline: 19519276]

14. Cooke M, Higgins J, Kidd P. Use of emergency observationassessment wards: a systematic literature review. Emerg Med J 2003;20(2):a. [doi: 10.1136/emj.20.2.138]

15. Lateef F, Anantharaman V. The short-stay emergency observation ward is here to stay. In: Am J Emerg Med. 2000;18(5); 2000:A.

16. Hoot NR, Aronsky D. Systematic review of emergency department crowding: causes, effects, and solutions. Ann Emerg Med 2008 Aug;52(2):126-136. [doi: 10.1016/j.annemergmed.2008.03.014] [Medline: 18433933]

17. Hong WS, Haimovich AD, Taylor RA. Predicting hospital admission at emergency department triage using machine learning. PLoS One 2018 Jul 20;13(7):e0201016 [FREE Full text] [doi: 10.1371/journal.pone.0201016] [Medline: 30028888]

18. Ting DS, Gunasekeran DV, Wickham L, Wong TY. Next generation telemedicine platforms to screen and triage. Br J Ophthalmol 2020 Mar 03;104(3):299-300. [doi: 10.1136/bjophthalmol-2019-315066] [Medline: 31796427]

19. Hildebrandt DE, Westfall JM, Smith PC. After-hours telephone triage affects patient safety. J Fam Pract 2003 Mar;52(3):222-227. [Medline: 12620177]

20. Gunasekeran DV. Technology and chronic disease management. The Lancet Diabetes \& Endocrinology 2018 Feb;6(2):91. [doi: 10.1016/s2213-8587(17)30441-2]

21. Ellis DG, Mayrose J, Phelan M. Consultation times in emergency telemedicine using realtime videoconferencing. J Telemed Telecare 2006 Jun 23;12(6):303-305. [doi: 10.1258/135763306778558187] [Medline: 17022838]

22. Brennan JA, Kealy JA, Gerardi LH, Shih R, Allegra J, Sannipoli L, et al. A randomized controlled trial of telemedicine in an emergency department. J Telemed Telecare 1998 Dec 02;4 Suppl 1(1_suppl):18-20. [doi: 10.1258/1357633981931911] [Medline: 9640721]

23. Kim SW, Madan J, Dritsaki M, Bryce C, Forjaz V, Fraser J, et al. Benefits and costs of digital consulting in clinics serving young people with long-term conditions: mixed-methods approach. JMIR Med Inform 2018 Oct 30;6(4):e48 [FREE Full text] [doi: 10.2196/medinform.9577] [Medline: 30377145]

24. van der Kop ML, Muhula S, Nagide PI, Thabane L, Gelmon L, Awiti PO, et al. Effect of an interactive text-messaging service on patient retention during the first year of HIV care in Kenya (WelTel Retain): an open-label, randomised parallel-group study. The Lancet Public Health 2018 Mar;3(3):e143-e152. [doi: 10.1016/s2468-2667(17)30239-6]

25. Gunasekeran DV, Wong TY. Artificial iintelligence in ophthalmology in 2020: a technology on the cusp for translation and implementation. Asia Pac J Ophthalmol (Phila) 2020;9(2):61-66. [doi: 10.1097/01.APO.0000656984.56467.2c] [Medline: 32349112]

26. Greenhalgh T, Koh GCH, Car J. Covid-19: a remote assessment in primary care. BMJ 2020 Mar 25;368:m1182. [doi: 10.1136/bmj.m1182] [Medline: 32213507]

27. Xie Y, Gunasekeran DV, Balaskas K, Keane PA, Sim DA, Bachmann LM, et al. Health economic and safety considerations for artificial intelligence applications in diabetic retinopathy screening. Transl Vis Sci Technol 2020 Apr;9(2):22.

28. Gunasekeran DV, Agrawal R, Testi I, Agarwal A, Mahajan S, Nguyen QD, Collaborative Ocular Tuberculosis Study (COTS) Group. Lessons in digital epidemiology from COTS-1: coordinating multicentre research across 10 countries using operational and technology innovation to overcome funding deficiencies. Ocul Immunol Inflamm 2020 Apr 22:1-7. [doi: 10.1080/09273948.2020.1744669] [Medline: $\underline{32320326]}$

\section{Abbreviations}

COVID-19: coronavirus disease 2019

SAVED: Safety and efficacy of follow-up for patients with abdominal pain using video consultation

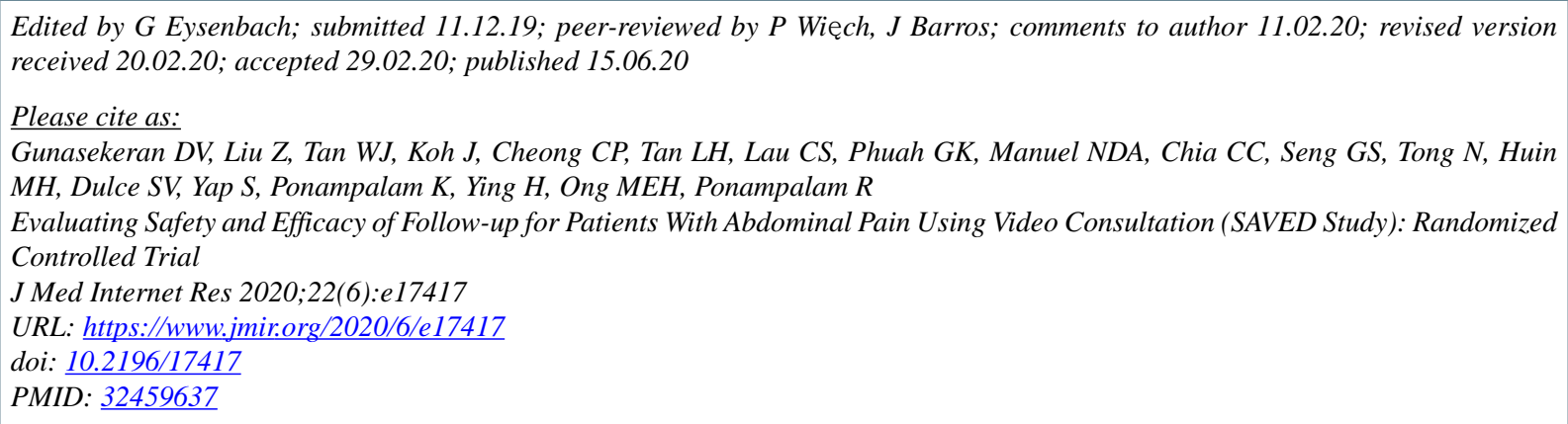


(CDinesh Visva Gunasekeran, Zhenghong Liu, Win Jim Tan, Joshua Koh, Chiu Peng Cheong, Lay Hong Tan, Chee Siang Lau, Gaik Kheng Phuah, Newsie Donnah A Manuel, Che Chong Chia, Gek Siang Seng, Nancy Tong, May Hang Huin, Suzette Villaluna Dulce, Susan Yap, Kishanti Ponampalam, Hao Ying, Marcus Eng Hock Ong, R Ponampalam. Originally published in the Journal of Medical Internet Research (http://www.jmir.org), 15.06.2020. This is an open-access article distributed under the terms of the Creative Commons Attribution License (https://creativecommons.org/licenses/by/4.0/), which permits unrestricted use, distribution, and reproduction in any medium, provided the original work, first published in the Journal of Medical Internet Research, is properly cited. The complete bibliographic information, a link to the original publication on http://www.jmir.org/, as well as this copyright and license information must be included. 